\section{SMALL SCALE STUDIO SETUP (4S) CREATION : CURRENT TRENDS IN ANIMATION INDUSTRY ENTREPRENEURSHIP}

\section{Fythullah Hamzah}

Universiti Malaysia Sarawak

\section{Ahmad Azaini Abdul Manaf \\ Universiti Malaysia Sarawak}

\section{Azwan Abidin}

Universiti Malaysia Sarawak

Corresponding Author amaazaini@unimas.my phytocomplex@yahoo.com
Self-employment and self-entrepreneurship activities among graduates in local and global economic trends lead to the birth of small scale animation studios. Government funding and business exposure in higher learning institutions are driving the young workforce to establish their own company rather than working for others. The current generations of graduates are very much in favor of entrepreneurship and begin to break away from the notion of stability in conventional professions due to the lack of flexible work-life balance and office benefits. Company ownership and financial freedom self-management remain the most recent phenomena in today's graduates. The idea of maintaining self-expression and control of the personal intellectual property is driving the young animator to venture into a small scale studio setup (4S).

Keywords: Small Business, Graduates, Animation, Studio, Entrepreneurship 


\section{INTRODUCTION}

\subsection{Establishing a Sustainable Model For Creative Graduate}

The new generation behavior is positively affected by technological change, globalization, and economic disruption. Among the factors are they are inclined towards tech and their gadget affinity helps shape their way of living. The current trends in the local and global economy resulting in the birth of small creative multimedia company, particularly animation. Malaysia ranked as the first most attractive emerging market in Asia and identifies as top investment destinations in the world, supported by the market-oriented economy and pro-business policies (Digital Economy Corporation, M. 2018). Government funding and alumni entrepreneurship success story exposure in universities are driving the young workforce to incorporate their own company rather than working for corporations.

\section{SMALL ANIMATION STUDIO SETUP TRENDS}

New media business all over the world is rapidly changing and evolving. Animation, VFX \& video games industry was estimated at US\$ 264 billion in 2019 with the projected growth in the animation industry the rate of 2-3\% (Newswire, 2019). Although global corporations make up most of the stakeholders, small businesses still maintained both growth and stability. Private companies are focused and more concentrated on a specific skill set and more versatile due to the nature of the compact size business and able to change to the appropriate exit strategy to match customer demand. This phenomenon is a direct result of studio flexibility and agility, meaning they can adjust and comply with their customer demand more effectively. Small studio leverage to maximize the open-source software as a way to stay lightweight and outpaced much larger organizations resulting in a more inexpensive price on the market (Manrique, 2015). Thus, this phenomenon enables us to consider and address the considerable potential of small studio setup. This paper discussed the advantages of small animation business setup venture on graduates and outlined the necessary model-based current trending animation industry practice in Malaysia.

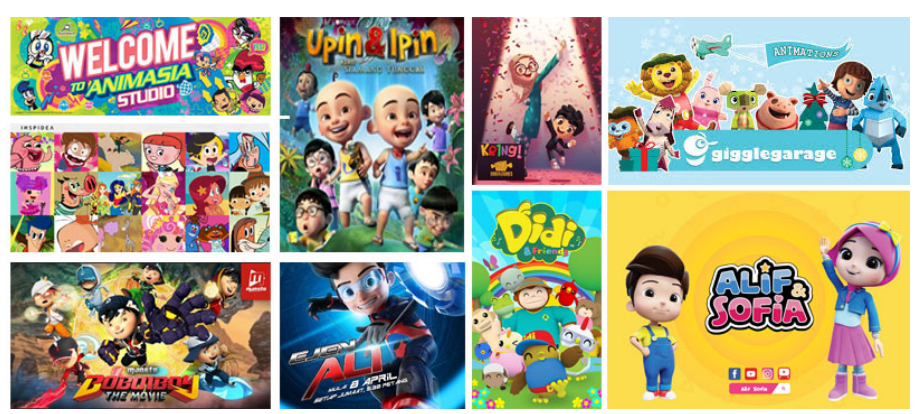

Figure 1: Malaysian animation companies and it's intellectual property. 


\section{STRATEGIC FACTORS OF A SMALL SCALE SETUP}

\subsection{Lower company overhead cost ensure a higher sales margin}

A small setup ensures a higher payment margin distributed throughout the company if properly guided. Typically, a group of digital talents tend to form small enterprises led by the founders. The small enterprises ecosystem has a variety of digital talents skills and multi-tasking capabilities. As a result, lower overhead ensures a minimum number of people working on the project.

Small enterprises may be paired with a range of small entities or associations to shape and sell a project that needs a bigger workforce. The benefits of partnering through strategic collaboration are by joining the established collaborative network. This can therefore shape the potential to meet the needs of their clients with the best ideas.

\subsection{Small businesses commonly adopt a narrow market focus}

Small scale studio typically focused on a specific animation genre. This is a characteristic surveyed by clients because they are usually seeking a content developer that possesses meaning and maintains a sense of purpose (Kuslich, 2014). A small company usually take one project at a time, and this advantage ensures a higher-quality output due to the nature of the small company that has the more senior workforce and high skill worker and work consistency. Specialized projects frequently offered a higher price due to the skillset demanded in the scope of work (Giardina, 2016). This is an ongoing trend in entrepreneurship among graduates that focusing on a specific type of animation and promoting a niche genre as a brand name for their company.

\subsection{Low Managerial Cost}

Minimum managerial personnel eliminates the unnecessary above the line cost that does not contribute to the project production. Nonlinear simulation and management can be introduced since the manpower is not that significant. For example, creative director and art-based manager can supervise managerial tasks without having a set of managers in the team, therefore eliminate over the line cost. Indeed, by reducing managerial positions, small companies are able to offer specialised benefits and incentives if they meet certain requirements. 
Cloud and big data development make the environment for digital network technologies feasible and cost-effecitve. With these communicative affordances of digital environment, rendering processes can be remotely monitored. This reduces overhead and expenses, because the operating costs are low, and multitask have been performed. Also, hardware and software can be rented on a project scale, reducing the need to purchase an equipment that will be out of date in three years.

\subsection{The $4^{\text {th }}$ Industrial Revolution Technology Leverage}

Tech-savvy small companies utilized the maximum capabilities of current technology. For example, cloud rendering undoubtedly reduces time and money invested in rendering exercise and makes it more efficient. This technological advancement eliminates the need for machines and manpower into the equation. In this context, multiple teams with a range of assigned projects can be done simultaneously, thus minimising documentation with human resources.

Growing cloud technology also affected industrial revolution infrastructure, where virtual office space, nomad workstation, and online meeting platform have become a new norm in current business trends. In this relation, fresh graduates are inclined to work remotely, tailored to the capacity of small studios with flexible work environment.

\subsection{Flexible Time and Nomad Office Setup}

Avoiding morning traffic is a convenient benefit for employees and also a factor that is favoured by young generation of workers to meet flexible working hours. However, this benefit offered only on a contractual basis. Normally, small setup companies operate within flexible hours and/or in submission-based and task-based settings. The former and the latter usually happen with a range of options.

Indeed, the growth of digital startups which use advanced wireless technologies, succeeded in adapting the 'work remotely' norm to gain time flexibility. In this sense, the young 'digital natives' represent a wide range of multitasking tendecies (Ettinger \& Cohen, 2019) and bring new insights on a remote-friendly work environment. Thus, the concept of a virtual office emerges from working remotely, empowering the future work of digital to grow. This approach significantly increases productivity and enables effiency of multiple tasks. 


\section{METHODOLOGY, VARIABLES AND DATA}

The research and analysis for this study were carried out in three phases:

\subsection{Cluster data collecting}

Phase one activity revolved around primary data gathering through quantitative surveys and qualitative interviews with companies' representatives in Klang Valley and Cyberjaya. The survey was focused on three segments:- company size, current project, and business projection. An interview with 15 companies with random size, background, and scalability are chosen for this study. Further information for a larger ASEAN demographic over the previous years was gathered by official governmentlinked institutions (Digital Economy Corporation, M. 2018).

\subsection{Analysis of Findings}

Phase two is an exercise identifying company characteristics. An overview will be published with the data tabulated gathered. These findings will be divided into two clusters according to the size and overhead of the company.

\subsection{Proposed Method}

Phase three concludes the finding and designed a business model to suggest for fresh graduates. This model is designed to make full use of current business trends and development.

\section{EMPIRICAL RESULTS AND ANALYSIS}

\subsection{Business Model Type in Typical Malaysian Animation Company}

From the preliminary interviews and literature findings, IP (Intellectual Properties) creation is very costly and would break the bank. Most of the businesses in creative ventures are either funded by investors or have a direct relationship with broadcasters. Companies and broadcaster bounded projected tasks for more than 5 years and bind by a contractual agreement. Small studios are more interested in outsourcing projects from another client (25\% direct and $18 \%$ indirect) and this accounts for more than $43 \%$ of the projects in the data. As a result, the studios has a more flexible option and therefore more time to focus on their pet projects. However, there a few animation studio practices licensing their IP to other companies (Digital Economy Corporation, M. 2018).

14 IJACA | Vol.3 | Issue 1| June 2020 
Malaysia Digital Economy Corporation (formerly known as Multimedia Development Corporation) is one of the authorities entrusted in the monitoring of digital content development growth in Malaysia. An overview of current animation trends was published in 2018 to present a clear view of the region's animation industry, specifically from the angle of development and production. It seeks to understand the region's industry landscape, scale, and value, as well as its global market reach and forecasted outlook. There are several practices trends in the animation business. Based on the statistical result in table 1 , indicate the majority of them creating their own IP, while $14 \%$ are co-developing with other companies to develop the content. The secondhighest number is work for hire from a direct source or as known as a sub-contractor. While the rest of the companies practiced licensing and other activities.

Table 1: Project Type in Malaysian Animation Company.

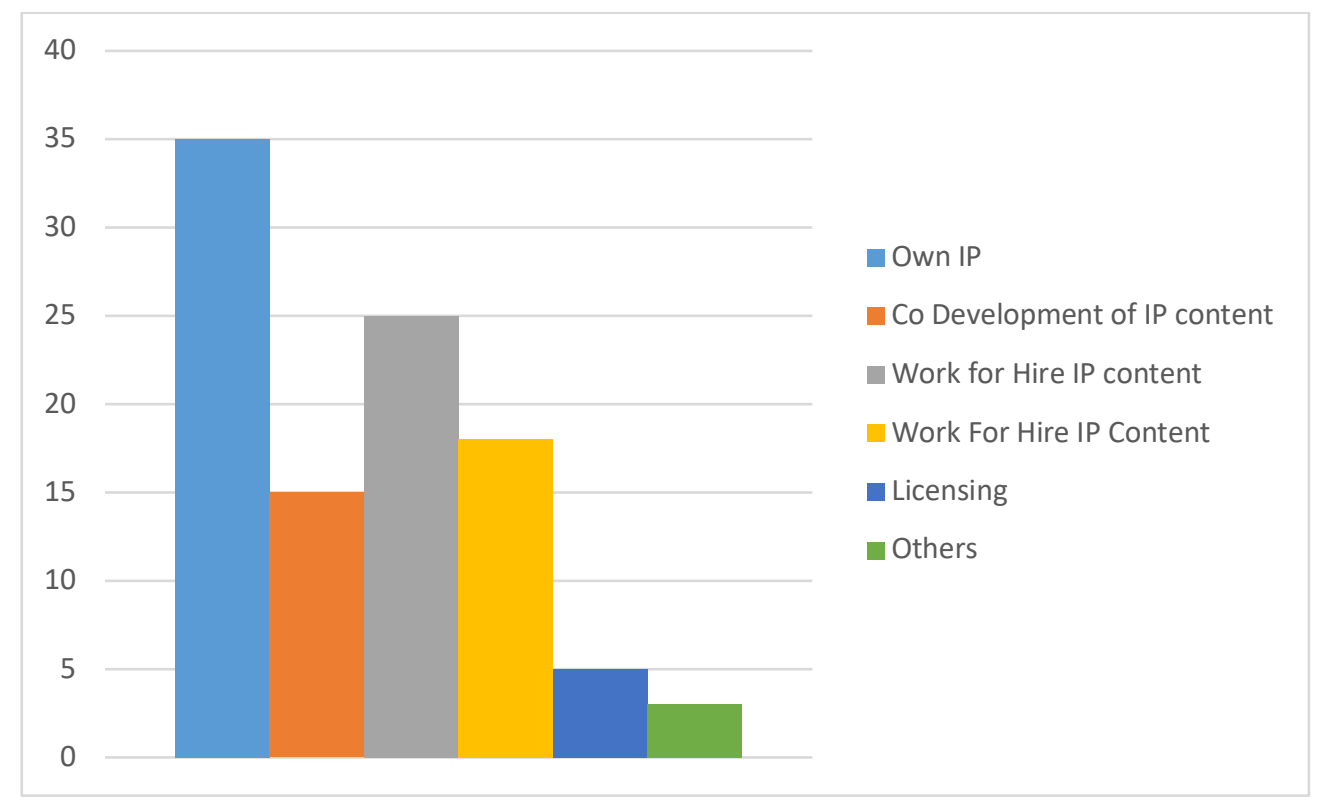

\subsection{Type Of Work Variations in Malaysian Animation Companies}

Small and big companies major has its own characteristics in its managerial style and approach. Big companies often adopted a pyramid structure in their organization while the former will resolve to a divisional studio management model. Typically, a company department is divided according to the role and function. While animators are the biggest number in the data collected, it is a known fact that big companies employed more managers to ensure a smooth pipeline. While multiple management posts in a large business make up 7\%, in reality, a large portion of the office budget is consumed by a cumulative salary for managers. Small business practice multitasking on multiple roles throughout the whole project and this eliminate redundancy and ensuring minimum paperwork with the human resources department. In fact, there are cases where the employees are assigned outside the specification of their work. For example, 
a storyboard artist also acts as a sound engineer and compositor. This implies that multitasking ability is a typical feature of small business setup in Malaysian animation industry. In other words, the multitask pattern describes the identification of creative industries mainly due to the reduction of employee and production cost (Yoon, 2019) and these insecure circumstances caused inequality in creative profession in animation industries.

Based on table 2, the animator produces the most substantial section in an animation company. This number reflects the importance of the production team (18.5\%) and preproduction (15\%) additional acquired data according to South East Asia Animation Report 2018 with combined population $\mathrm{N}=68$. Interestingly, pre-production stages, such as storyboard artist and scriptwriters indicated as 15\%, shares the second significant position in an animation company.

Table 2: Position and Role Distribution in Animation Companies.

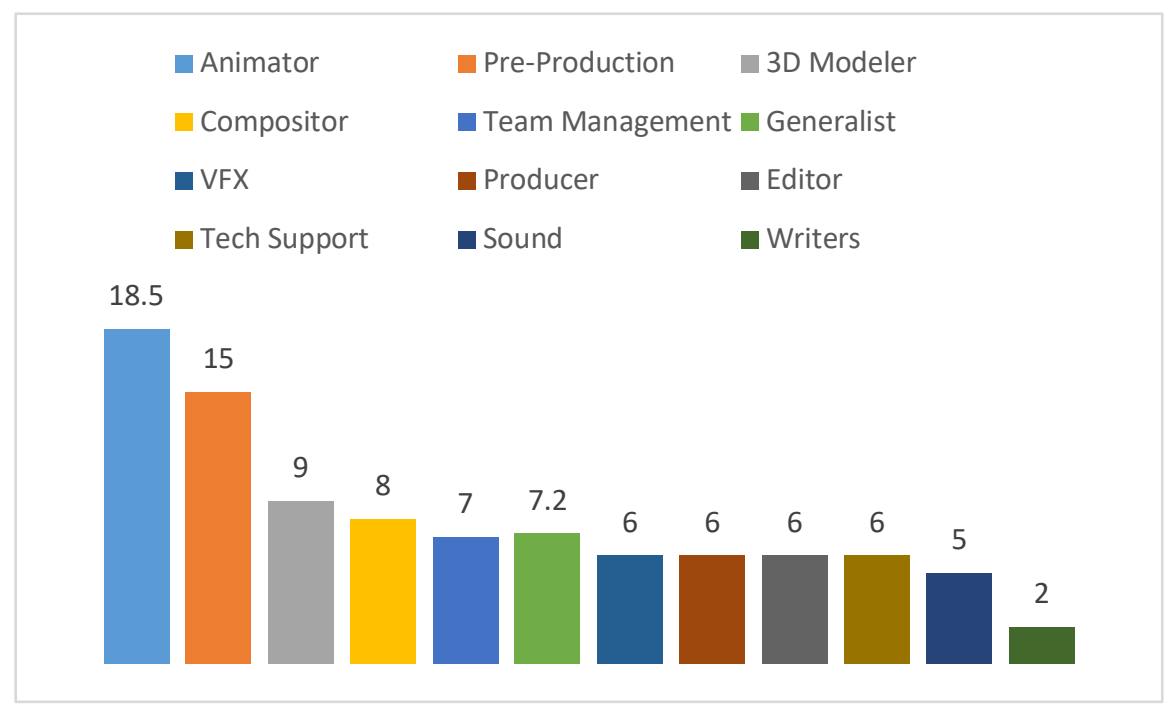

\subsection{Salary Range in Small Companies}

The company size determines the range of profit and salary. Small companies normally recruit more skilled employees and eliminate preliminary training for inexperienced graduates. The experienced team was able to work efficiently without continous supervision and remove the need for many managers.

In table 3 indicated that the largest salary range comes from animators and according to the previous report for positions based in Malaysia (Digital Economy Corporation, M. 2018).

Table 3: Overall Salary Overview in Small Animation Companies. 


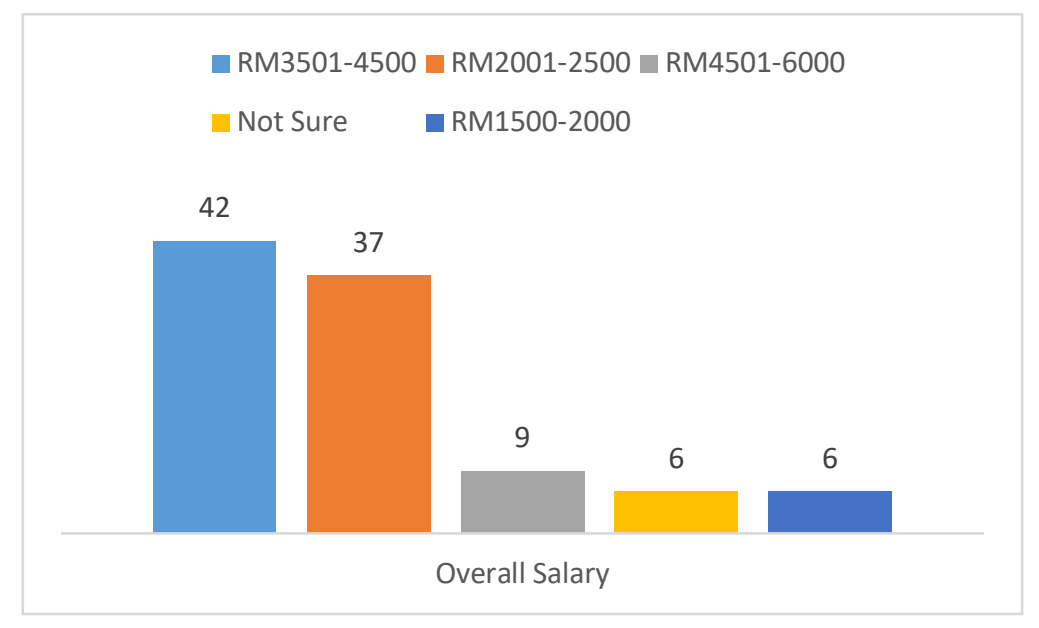

\section{DISCUSSION AND CONCLUSION}

As a result, previous studies and business models runs by a smaller company and find success were reiterated by a previous study (Bendazzi, 2015), where a small animation studio can make a huge difference in the competitive market. There is no doubt that further challenges will arise along the way. Smaller businesses are willing to take a pragmatic and measured approach to have a good chance of thriving in the future. Based on the findings, there are few considerations and recommendations for graduates and youths venturing animation business such as:

\subsection{Low risks Concept}

Creating a business plan that does not break the bank. Most small companies operate on a maximum capacity with lower monthly operational expenses. This can leverage more payment for artists and more quality work (Gray, 2017). As animation production is goal-oriented, timeframe-consuming and financially-driven (Collier, 2019), maintaining a small footprint while keeping the niche market high will provide high profit. In other words, all progresses in animation production involve substantial risks, costs and infrastructure that have to be restructured. In this sense, the cloud computing flexibility also provides more accessibility which brings the production to another stage. By strategizing the animation team for more mobility and work flexibility, which translates into less need for large office space, small scale studio can rent a coworking space at a fraction of a price and cost effective.

In addition, working remotely in flexitime from home boosts job satisfaction, which also linked to increases work efficiency (Kröll and Nüesch, 2019). This indicates that flexibility is the main factor of small scale studio innovation to fulfill industry needs. 


\subsection{Financial Overview}

It is necessary to have a financial review, and determine how the company and project size will accelerate. The graduates must grasp the financial model of small studio setup and observe the budget closely with proper assessment of accounting. This means graduates must learn about contigency strategies from contractual agreements and truly understand their work scope. This can be achieved with the guidance of a legal firm or consultation with other professionals in the industry network. Consequently, a small company must create a benchmark to maintain a profitable business that ensures a good profit margin and preserves the capital for the next ventures.

\subsection{Define the Company's Legal Status}

Legality and good contractual practice are essential in order to protect the contract with the client. Small businesses, particularly small-scale animation studios, would not allow themselves to be trapped in open terms contracts that would end up draining their resources. While a small company can build experience through smart cooperation, the extend of collaborative work between those parties must be written. Graduates will expand their company to the big game and possibly expand their workforce to maximise capacity, given the right investors or collaboration with corporate entities. This would happen sooner or later depending on the economy situation. At the time of this writing, our nation face with Covid-19 global pandemic and large enterprises suffer while small animation studios still constantly busy with the medium-scale jobs (Grater, 2020). In fact, the social distance limit during the Covid-19 pandemic does not actually affect the production of animation (Ellis, 2020).

In conclusion, this discussion ends with career expeditions of potential graduates from freelancer jobs and eventually turns into owners of a business. In fact, to boost the creative economy intensively, government-based agencies offer a range of assistance and financial support for small companies, thus providing creative enterprises with a golden opportunity. It does not end here, however, it is important to consider the solid fundamentals of entrepreneurship for broader benefits in animation industry. In particular, fair accountability for both creative workers and management, which must be a fundamental principle of company owners, is a major element of corporate honesty to contribute and encourage the growth of creative economy.

\section{ACKNOWLEDGMENT}

This research and article were supported by Scholarship of Teaching and Learning (SoTL) Grant No: SoTL(A)/FSGK/2019(2)/027). 


\section{REFERENCES}

1. Bendazzi, G. (2015). Animation: A World History: Volume lii: Contemporary Times (pp. 30). Focal Press.

2. Collier, S. (2019). Preparing creative industry graduates for a career in high pressure industry: An animation practitioner's perspective. $13^{\text {th }}$ International Technology, Education and Development Conference (pp. 3492-3498), Valencia: IATED

3. Digital Economy Corporation, M. (2018). Enter Malaysia. Cost of Doing Business. Retrieved from https://mdec.my/wp-content/uploads/ENTER-MALAYSIA-Final2.pdf

4. Digital Economy Corporation, M. (2018). South East Asia Animation Report 2018. Kuala Lumpur. Retrieved from https://mdec.my/wp-content/uploads/SEA-layout20180815.pdf

5. Ellis, E.G. (2020, May 10). Quarantine is a weirdly good time for animation. Retrieved from https://www.wired.com/story/animation-tv-covid-19-coronavirus

6. Ettinger, K., \& Cohen, A. (2019) Patterns of multitasking behaviours of adolescents in digital environments. Education and Information Technologies, 25 (1), 623-645.

7. Giardina, C. (2016). Oscar's Animation Throwdown: Big Studios Battle Small Indies for the Gold. Retrieved April 25, 2020, from https://www.hollywoodreporter.com/behind-screen/oscars-animation-throwdownbig-studios-battle-small-indies-gold-949093

8. Grater, T. (2020). Coping With COVID-19 Crisis: China's Emmy-Winning Base FX On Keeping A Global VFX \& Animation Outfit Running In Turbulent Times. Retrieved from https://deadline.com/2020/03/coping-with-covid-19-crisis-chinabase-fx-keeping-vfx-animation-outfit-running-1202893043/

9. Gray, R. (2017). How Small Studios can be your BIG break. Retrieved from https://www.skwigly.co.uk/how small-animation-studios-can-be-your-big-breakpart-1/

10. Kröll, C., \& Nüesch, S. (2019). The effects of flexible work practices on employee attitudes: evidence from a large-scale panel study in Germany. The International Journal of Human Resource Management, 30(9), 1505-1525.

11. Kuslich, S. (2014). How to Run an Effective Production Company. Retrieved 2020, from https://ghostproductions.com/blog/animation/how-to-run-an-e/

12. Liang, H., Sit, J., Chang, J. and Zhang, J.J., (2016). Computer animation data management: Review of evolution phases and emerging issues. International Journal of Information Management, 36(6), pp.1089--1100 
13. Manrique, M. (2015). Blender for animation and film-based production (pp. 49). London: CRC Press.

14. Newswire, P. (2020). Global Animation, VFX \& Video Games Industry: Strategies, Trends \& Opportunities (2020-2025). Retrieved from https://www.prnewswire.com/news-releases/global-animation-vfx--video-gamesindustry-forecast-2020-2025---the-market-was-valued-at-264-billion-in-2019300989543.html.

15. Yoon, H. (2019). Do higher skills result in better jobs? The case of the Korean animation industry. Geoforum, 99, 267-277. 